\title{
BOTANIC GARDEN PROFILE Inverewe: gardening on the edge
}

\author{
Kevin L. Frediani ${ }^{1}$
}

\section{Abstract}

Set in the heart of the Scottish Highlands, Inverewe is one of the most spectacular garden locations in the UK. Situated beside the A382 on the North Coast 500 tourist route, the property receives over 100,000 visitors each year, drawn to see a diversity of plants and to enjoy the breathtaking backdrop of mountains and seascape it affords. Since its first plantings in 1864, the property has been a centre for experimental approaches to establishing and growing tender woody and herbaceous perennials, while a diaspora of alumni have gone on to fulfil prominent roles in the horticultural industry over the years. The garden today covers approximately 22 ha of mainly woodland gardens, renowned for the diversity of their designed elements and whose conservation management is based on a thorough understanding, appreciation and analysis of the garden's historical development and its significance in local, regional and national contexts.

In recent years, Inverewe has faced a number of challenges related to the growing impact of global change, with increased occurrences of extreme weather events, and emergent pest and disease incidents associated with climate change and the movement of plants and their vectors, which include human-aided transport of problems between sites. In this context, this article provides a lens on the drivers of change that the plant collection is facing in the early decades of the 21 st century. After an introduction to the garden, its evolved collections and management approach, three case studies are highlighted as examples of emerging threats to Inverewe as a garden and work of art. Inverewe is presented as a landscape that endures through adaptation to social, economic and, increasingly, environmental challenges that shape the direction it takes as a garden and plant collection growing on the edge.

\section{Introduction}

Over its 156-year history, Inverewe has been established as a heritage garden, designated in the Inventory of Garden and Designed Landscapes for its pioneering work on the development of gardening on Scotland's remote western seaboard (HES, 2017). The layout of the gardens, Woodland Garden and Walled Garden are ascribed high value as a 'Work of Art' (HES, 2017). The garden sits within 850 ha of land which is recognised through national designations for the wildland and wildlife it supports. These designations include a Site of Special Scientific Interest (for quality of habitat), Special Protection Area (for birdlife) and a Marine Protection Area, and the land is also part of the wider cultural landscape of Wester Ross, providing a gateway to the recently designated UNESCO Biosphere Reserve.

Inverewe is celebrated for its informal garden design, cut along natural contours

${ }^{1}$ Kevin Frediani is Operations Manager at Inverewe, which is owned and run by the National Trust for Scotland. Address: Hermiston Quay, 5 Cultins Road, Edinburgh, EH11 4DF, UK.

Email: kfrediani@nts.org.uk 
of plants to explore and evaluate in the context of informing resilient landscapes in a changing climate. The extensive plant collections include examples of international importance, with notable collections of elepidote (large-leaved) rhododendrons and Australasian plants, the national collections of Olearia and a collection of Brachyglottis that is in the process of being reconstructed (Grant, 2014; Plant Heritage, 2019). The Garden Vision is to 'conserve and promote Inverewe as a world-class heritage garden', providing a place to experiment and record the genetic and physiological capacity of the temperate plants it cultivates and introduce new species each year (Mackenzie, 1908; Cowan, 1964; Frediani et al., 2019). Inverewe is a garden full of ambition, informed by history and place, some of which is constraining, such as being exposed to some of the most extreme weather on the mainland UK, and where wind is more limiting than rain (Darling, 1945). It is also a garden that has become host to novel pests and diseases in recent times and this has already changed the approach being taken to inform the future collection by impacting the viability of once important plantings, including functional shelter trees. These issues are discussed in the context of a number of case studies that frame the emerging challenges to an established heritage garden.

\section{Gardening on the edge}

A garden has been modestly defined as a piece of ground adjoining a house, in which grass, flowers, and shrubs may be grown (OED, 2019). Inverewe has continuously been gardened although its central house has changed the atmosphere of the garden over the years following the loss of the highland manorial lodge in 1914 and the later construction of an Arts and Crafts home for Mairi Sawyer in 1937 (Butler, 2018). Indeed the intervening years had seen the ruin become the focus for Mairi to create her 'burnt garden', with more than a passing influence from the neoclassical style, over a number of years after the original mansion burnt down in 1914, until a new home was constructed following her second marriage in 1935 to Ronald Sawyer (Fig. 2). An immersive museum and art gallery fill that space today, providing the beating heart to the garden and enabling visitors to make sense of the space following a short unoccupied period during the early years of the 21st century (Walsh, 2016; Studio LR, 2019).

This is a space that has been continually worked and crafted over an extended period stretching more than 150 years around a central feature that has itself changed over time, rather than a space that has been formally designed (Grant, 2014; Butler, 2018). From the most unlikely of origins, its edaphic and climatic environment has been modified from thin peat soils lying over some of the oldest impermeable rock found in Europe, into productive soils today capable of supporting a number of notable UK \& Ireland champion trees (Barber et al., 1978; HES, 2017). This was a feat that yielded results early on; within 40 years of creating his garden, Osgood was reporting on a very broad range of unusual plant material that was to be found growing there (Fig. 3). This was facilitated through the moderating influence of the Gulf Stream that much improves the weather experienced on the western landmass of the UK and Ireland (Mackenzie, 1908), affording cultivation of plants otherwise only grown outdoors in the extreme southerly counties of Devon and Cornwall (Grace, 1987). Long trialled for suitability, today these include Agapanthus and Watsonia from South Africa; 


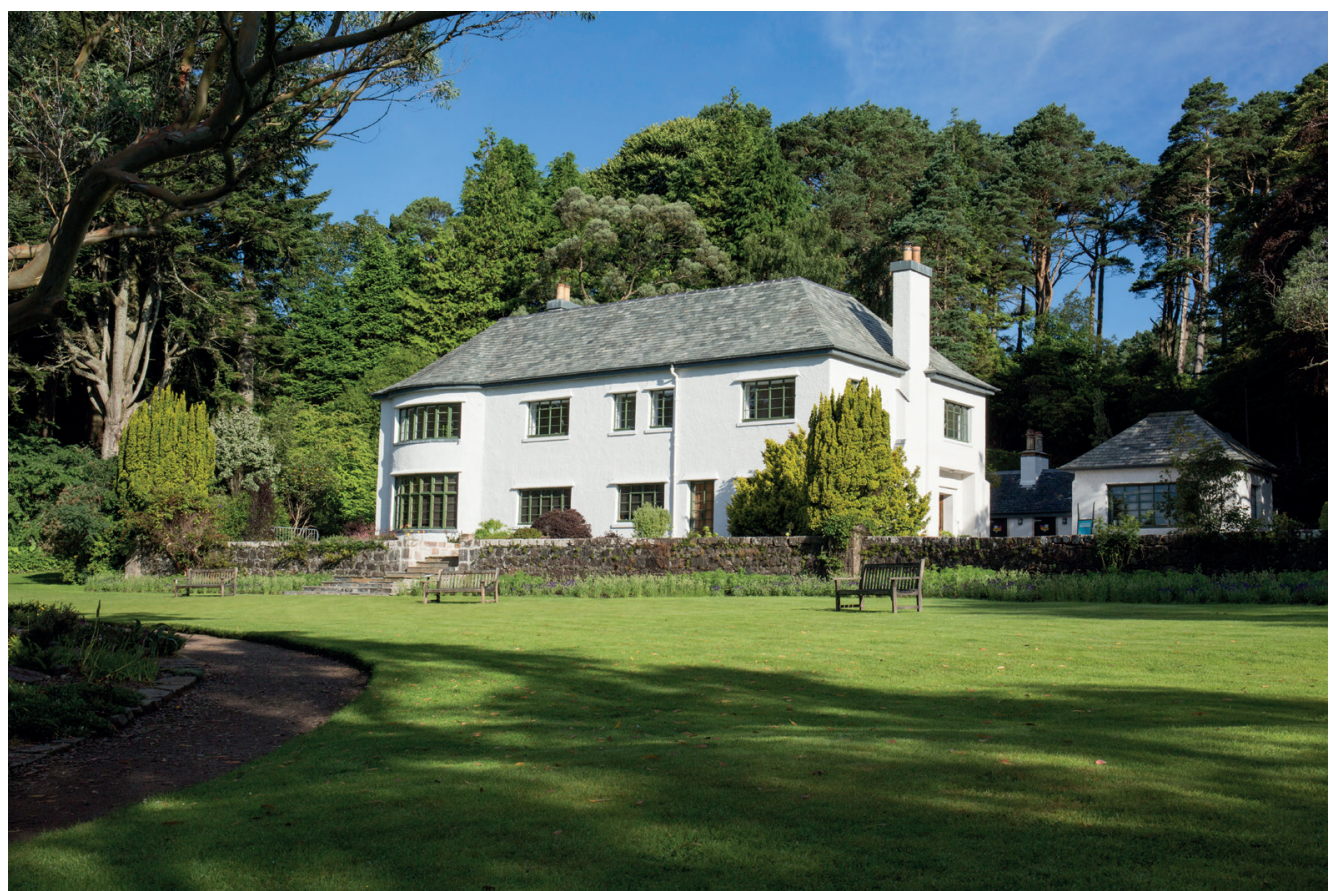

Fig. 2 The second Inverewe House set the final spirit of Inverewe through its construction in the Arts and Crafts style in 1937. Renovated and then opened to the public for the first time in 2016, it provides a museum and art gallery with an immersive approach to visitor experience informed through the written words and artefacts left behind by Ronald and Mairi Sawyer. Photo: Kevin Frediani.

\section{Crinodendron and Lapageria from Chile;} Trachycarpus from China; Metrosideros from New Zealand; and Rhododendron flowering in every month of the year (Sawyer, 1953; Butler, 2010).

The prospect of growing such a wide diversity of plants is a function of the ecological characteristics of the plants related to the climatic tolerance of their temperate distribution and the specific alignment to the microclimate that has been created by the gardeners. This is the skill of gardening on the edge: the genius of Osgood Mackenzie and Mairi Sawyer that was learnt through doing, the product of experience borne of travel and observation of plants in the wild. This would be followed by trialling locally, requiring a thoughtful approach to selecting, designing and managing plants (Sawyer, 1953; Hitchmough
\& Thoday, 2004). Nowadays this same garden craft is taught and maintained, and plant selection is helped by an evidencebased application of the principles. This helps to foresee improved alignment to the isometric lines of climatological variables through informed specification (Grace, 1987; Hitchmough \& Fieldhouse, 2004). However, while the amenity is being celebrated by visitors who see the introduced plants in the garden, these same garden plants, sourced from around the world, together with the mild environment provides opportunity for novel pests and diseases to be introduced and then, if conditions are right, to establish.

\section{A garden forged in an unpredictable environment} Inverewe and its surrounding area have been subject to major environmental and 
biological incidents over the years (Table 1). Many of these events have been due to extreme weather where high winds or substantial rainfall occurred. These required the garden to accept enforced change or modification to the use of the garden area by adapting or creating new features such as the Wet Valley that was formed from a series of wind blow events starting in the 1950s (Clough, 2001). However, a review of the conspectus of incidents at Inverewe over the years reveals a marked increase in the frequency of extreme events and the emergence of novel pest, disease and weed occurrences over recent years.

The impact of such enforced change to the collections has been extreme, and a number of notable groups of Inverewe iconic species that would previously have been worthy of specialist collection status have now become hard to cultivate through reduced populations or loss of vitality. There is a loss of aesthetic presentation in diverse groups such as Meconopsis and Rhododendron as a result. This effect extends to the very fabric of the garden, with structural plantings such as Larix decidua (larch). This species comprises much of the eastern aspect of the garden and was hugely compromised when Phytophthora ramorum infection was confirmed in autumn 2015. Two thousand trees had to be felled in spring 2016 under a statutory Plant Health Order (Table 1 \& Fig. 4).

Such enforced change was foreseen in terms of broad trends, as evidenced by the early millennial projected impacts of UK gardening in a climate that is undergoing anthropogenic climate change (Bisgrove \& Hadley, 2002). Indeed, in the light of such forecasts and with mounting evidence made by local observations of increasing incidents at the property, some considerable effort

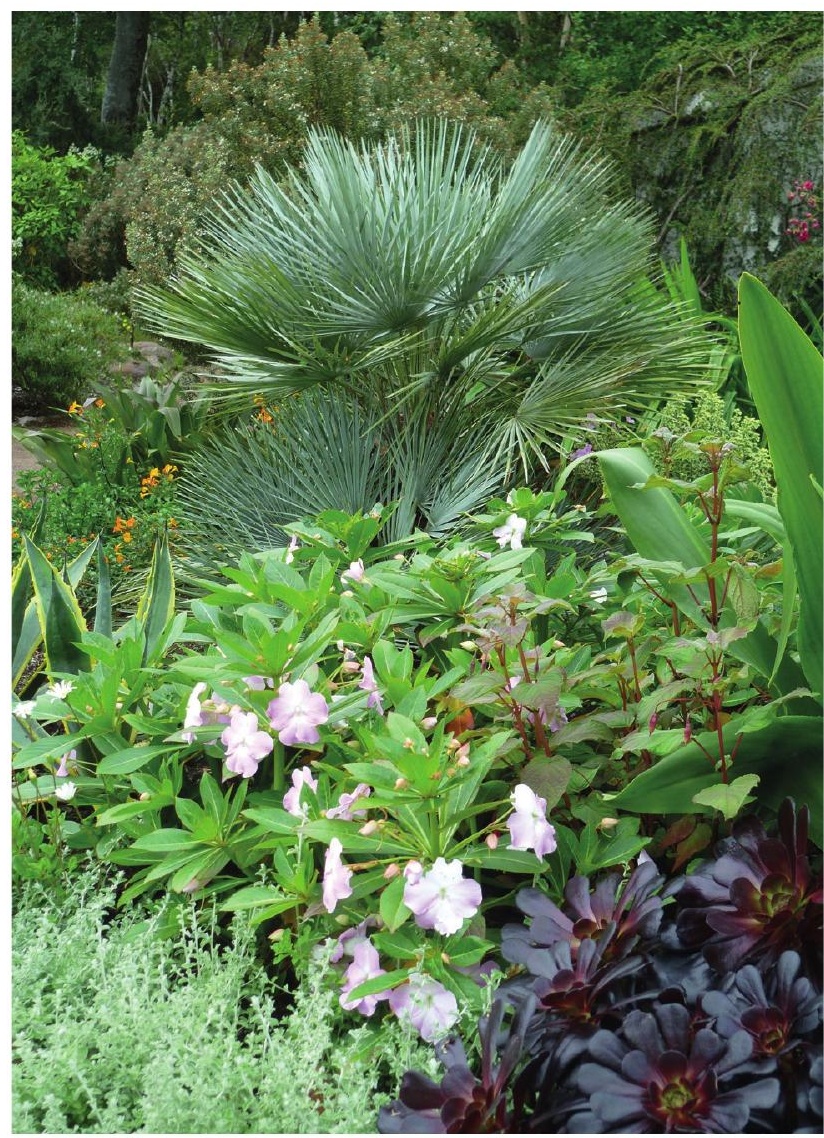

Fig. 3 The diversity of plants and flowers that grow at Inverewe is extraordinary. The moderating influence of the Gulf Stream allows the garden area named South Africa to provide a profusion of flower and texture rarely found outside the counties of Devon and Cornwall. Here, Chamaerops humilis (dwarf fan palm) is underplanted with Impatiens walkeri and an edging of Helicrysum microphyllum 'Silver Mist'. Aeonium 'Zwartkop' provides a purple accent while on the far left young plants of Agave americana 'Variegata' are helping provide vertical elements to this exotic view. Photo: Kevin Frediani.

has been directed into building resilience in the garden's operations and collection. This includes mitigation to reduce the potential loss of conservation collections through the propagation of historic plantings, and further diversification through the cultivation of new plant species and varieties. This was assisted with the investment, in 2016-2017, of $£ 500,000$ in a purpose-built biosecurity facility and major glasshouse 


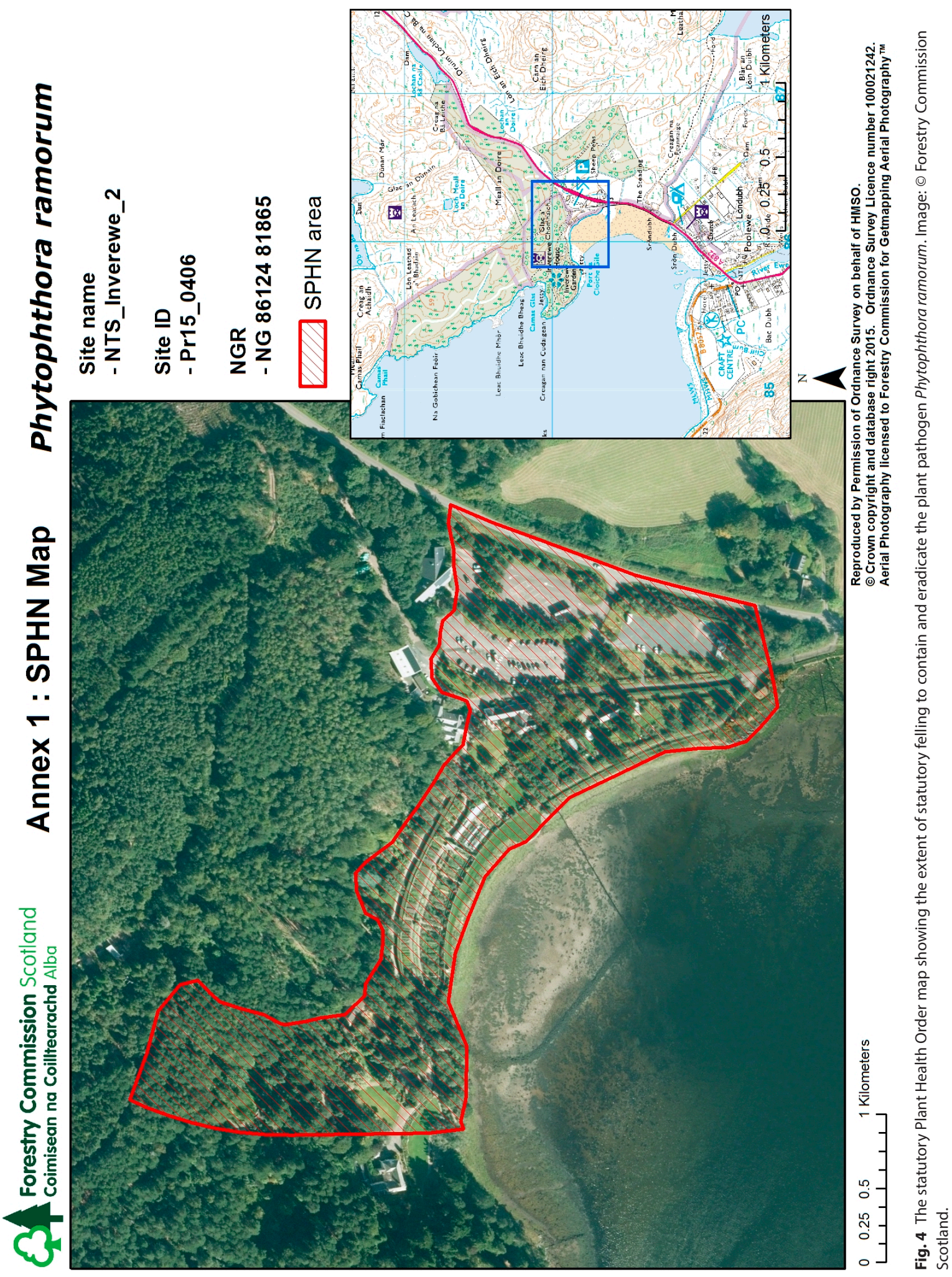




\begin{tabular}{|l|l|l|}
\hline \multicolumn{2}{|c|}{ Timelines and major events } \\
\hline Event & Years & Comment \\
\hline $\begin{array}{l}\text { Garden } \\
\text { founded }\end{array}$ & 1894 & Initial planting of shelterbelt \\
\hline $\begin{array}{l}\text { Severe } \\
\text { wind }\end{array}$ & $\begin{array}{l}1920 ; 1952 ; \\
1953 ; 1989 ;\end{array}$ & $\begin{array}{l}\text { Episodic wind has been a constant threat to the garden with the } \\
\text { high recorded winds of 120 mph (1989) }\end{array}$ \\
\hline $\begin{array}{l}\text { Severe } \\
\text { cold }\end{array}$ & $\begin{array}{l}1946 ; 1947 ; \\
2010\end{array}$ & $\begin{array}{l}\text { Extended and harsh cold weather is a rare event but can be } \\
\text { catastrophic due to the experimental nature of planting at } \\
\text { garden. } \\
\text { Note: 30-year trend is less intense and severe cold winters } \\
\text { (Scotland's Environment, 2019) }\end{array}$ \\
\hline $\begin{array}{l}\text { Pest } \\
\text { outbreaks }\end{array}$ & $2007 ? ; 2011$ & $\begin{array}{l}\text { Golden root mealybug (see Case study 2: potentially 2007, 12 } \\
\text { years before Scotland's first official record) } \\
\text { Cottony camellia scale insect (see Case study 3: 2011) }\end{array}$ \\
\hline $\begin{array}{l}\text { Disease } \\
\text { outbreaks }\end{array}$ & $2007 ; 2015$ & $\begin{array}{l}\text { Initial infection on ten shrubs was isolated and controlled through } \\
\text { removal and burning; a later infestation required 2,000 larch trees } \\
\text { to be prematurely felled (see Case study 1) }\end{array}$ \\
\hline Severe rain & 2017 & $\begin{array}{l}\text { Paths washed away in an overnight torrent of episodic rain. } \\
\text { Note: 30-year trend is increased days of heavy rain (Scotland's } \\
\text { Environment, 2019) }\end{array}$ \\
\hline
\end{tabular}

Table 1 Timeline of severe weather events and notable dates for pests and diseases.

complex. Internal NTS guidance and garden policies have helped to inform proactive management with regard to emerging pests and diseases, and have resulted in targeted interventions to avert the escalation of potential challenges such as biosecurity in order to reduce risk with novel pests and diseases (Cosgrove, 2017; NTS, 2013). The approach that has been adopted aims to promote, protect and conserve the collections within a heritage garden through adaptive management approaches that ensure the garden remains a major public amenity and the property protects the heritage conservation assets as highlighted within the 2014 published Heritage Garden Management Plan (Grant, 2014; Frediani, 2018).

\section{Case studies at Inverewe}

In setting the scene to understand the following pest and disease case studies, it is important to understand the context in which the garden operates. As a built heritage property within Scotland's national living and cultural heritage charity, Inverewe as a garden and estate property is tasked with being a positive contributor to the overall income of the organisation. This requires not only striving to do the right thing environmentally and socially but also ensuring that operational costs are less than income each year. This includes absorbing losses such as staff time when problems arise and puts a focus on the properties to proactively manage on-site risks through hazard identification and management to 
ensure operational objectives are fulfilled efficiently. That said, problems arise that are unforeseeable in magnitude or frequency and Inverewe has been affected by a number of pests, diseases and invasive non-native plants in recent years. External funding has been required to address these or make changes where they could not be contained. Three of these events will be explored to provide insight into the evolving approach to building resilience, rather than treating symptoms, for a collection that has been selected to be at the edge of its unnatural growing range.

It is also important to put Inverewe in the context of the portfolio of NTS: advisors guide policy which puts significance on the extent of monitoring and control of managed land to ensure that hazards associated with the garden collection are minimised, such as "avoid the unintentional escape of Invasive Non-Native Species" (Grant, 2014). Such guidance also stresses that the impacts of extreme weather causing visible damage to historic designed landscapes, gardens and areas of countryside under NTS operational

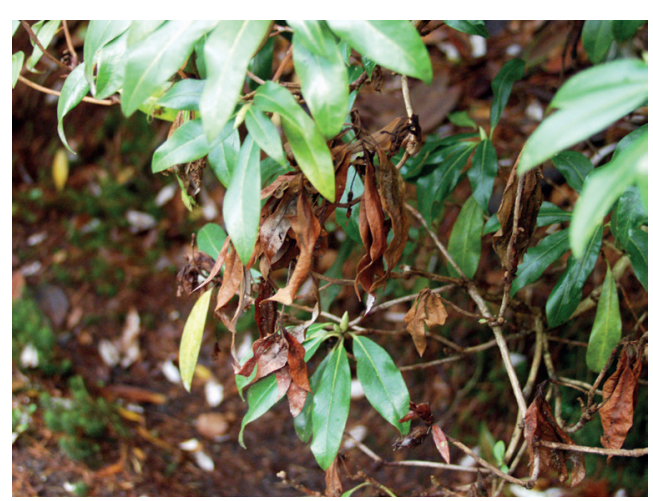

Fig. 5 Phytophthora ramorum infection showing typical symptoms on a rhododendron, including leaf-blackening, wilted shoots and dieback. On individual leaves, the blackening of the leaf stalk usually extends into the leaf along the mid-vein, although blackening at the leaf tip can also occur. The progress of the disease can be so rapid that shoots wilt and the leaves hang down. Photo: Kevin Ball.

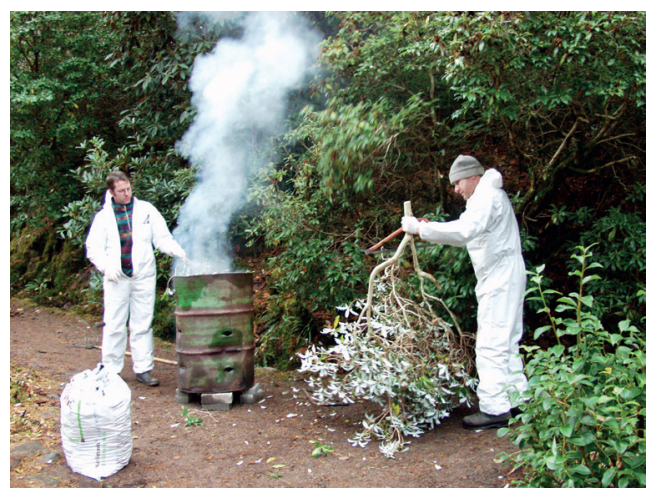

Fig. 6 Phytophthora ramorum infected Rhododendron zaleucum being burned following phytosanitary guidance at the time of notification in 2007. Photo: Kevin Ball.

management should be minimised or mitigated for (NTS BC04, 2013). In practice, however, this is proving more challenging to achieve than the principles would suggest.

\section{Case study 1: Phytophthora ramorum (sudden oak death)}

This case study highlights the costs of managing a notifiable pathogen in the UK that was found at Inverewe and has a potential commercial and ornamental impact on the national ornamental and commercial growing sectors, due to its wide host range of susceptible plants (Sansford et al., 2008).

On 15 December 2015 Inverewe was issued notice under Article 31(4) of the Plant Health (Forestry) Order 2005 to organise felling of plants infected or suspected to be infected with Phytophthora ramorum (sudden oak death), a disease not normally present in Great Britain and in respect of which there is danger of it spreading or being spread in Great Britain requiring enforcement of the clearance of infected trees in a defined area (Fig. 5). The presence of sudden oak death was confirmed on Larix species root, stem, bark, shoot and needle infections and is suspected of being present on Rhododendron ponticum and other plants in the soil (Fig. 6). 
Article 35 of the Order required NTS not only to fell over 2,000 mature trees but to inform the local Forestry Commission Inspector by 30 June 2016 and annually thereafter for a period of three years (until winter 2019) whether the measures required to control the outbreak have been complied with and to provide information on the details of the steps taken to comply with them (Fig. 7). Meanwhile the garden has been under strict biosecurity measures and will remain so until a final notice is dispensed confirming that the site is clear; official confirmation is expected in winter 2019.

In planning for change, no one can know when an incident or outbreak will happen or what its impact will be. However, the existence of a comprehensive shelterbelt plan which had been updated and published as part of the Heritage Garden Management
Plan in 2014 showed foresight, and with some modification proved to be of value in informing the mitigation approach that was subsequently taken (Grant, 2014). It identified coupes across the shelterbelt which would be thinned and planted up as part of a continuous cover approach to ensure this resource would remain in place for future generations of property staff to benefit from. However, it required some reflection and modification in the light of the Phytophthora infection and the emerging threat of Dothistroma septosporum (red band needle blight) during the intervening period on nearby Lewis and Harris, where it has infected all pine plantations on the islands. Therefore the property team undertook a broad review of plant solutions before agreeing restocking options, and the original plans have been tested for their fitness for purpose.

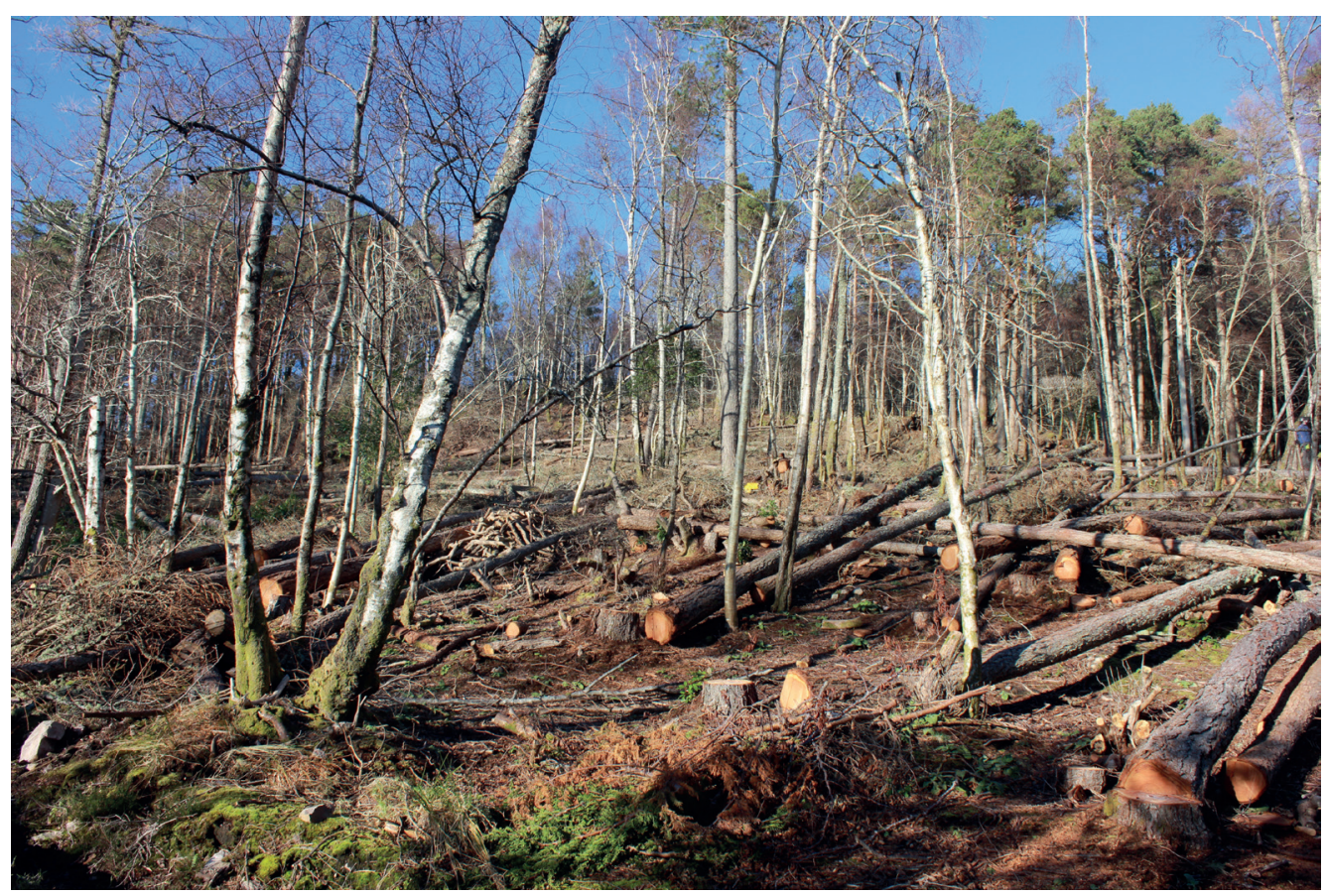

Fig. 7 The impact of disease and its control can be dramatic on a garden. This image records the core zone that was infected with Phytophthora ramorum and resulted in 2,000 larch trees being felled. Their branches were removed and burnt and the understorey of rhododendrons was removed. Regrowth was treated with pesticide to comply with the Statutory Notice enforced at Inverewe in 2015. Photo: Kevin Frediani. 
The principal requirement from the statutory regulators (the Forestry Commission) within the post-infection period guidance specified the need to create a closed canopy as quickly as possible and not to leave bare ground, by planting rather than waiting for natural regeneration to fill the gaps. This requirement aligned with the property's favoured management approach in the shelterbelt, so no significant change was required to the plans other than the felling and subsequent planting of the infected area. This moved the original plans forward a few years, as the area was not due to be felled until 2020. Serendipitously, the infected area had the least impact on the garden shelter, as it occurred on the leeward side of the estate and avoided the most significant structural trees. This, while good for the garden, has been economically unfortunate for the property to bear. ${ }^{2}$

Initial research into species that are vulnerable to sudden oak death and should be avoided was carried out via a literature search, while the Forestry Commission Ecological Site Classification tool assisting with the selection of species also considered their suitability for the site conditions (ESC4, 2019). Initial selection was also guided by reference to the National Vegetation Classification as a guide for ecologically appropriate vegetation, while site specific reference was undertaken to the composition and performance of nearby semi-natural woodlands on similar soil types (Rodwell, 1991). This resulted in the suggestion of a canopy of Pinus sylvestris (Scots pine), although not as a continuous planting due to needle blight concerns highlighted earlier, with intermingling of Quercus robur (oak) of known regional provenance and an understorey of Betula pendula and B. pubescens (birch) and Salix sp. (willow). Alnus glutinosa (alder) is encouraged and planted to recreate carr woodland in the wetter flushes.

In other areas of the shelterbelt where the juxtaposition to the garden is closer, more diverse species of exotic provenance were trialled from other temperate rainforest regions of the world, helping to identify zones of potential for future suitability using an approach first promoted for selection of urban street trees through phytosociological and climatic review (Röhrig \& Ulrich, 1991; Sjöman et al., 2010).

\section{Future focus}

Tree diseases are a national area of concern. The impact of global change is putting Inverewe in a leading position to prepare for change, to monitor and evaluate success, and to help others in the future. This work is in turn underpinned by international networks, and should include the selection of species for the garden areas adjacent to the main shelterbelt that are already being guided through the use of i-Tree Eco software (i-Tree, 2019) to quantify the structure and environmental effects of shelterbelt trees, and calculate their value to garden through ecosystem service provision (Frediani et al., 2019). Data from the i-Tree Eco survey that was undertaken by staff and volunteers in 2017-2018 is ideally placed to help inform effective resource management decisions, to refine property strategy and set priorities for the garden shelterbelt trees and estate woodland. This would enable the optimising of ecosystem

\footnotetext{
${ }^{2}$ The cost of felling the infected larch, its extraction and the subsequent treatment and removal of all understorey Rhododendron has been in excess of $£ 80,000$ to date. Three dedicated staff were required to focus on all tasks to ensure the statutory notice was completed within the three-month period, and this impacted significantly upon other planned duties.
} 
service provision while reducing any tension between ecosystem service provisioning and ecological integrity related to the role of native species by recognising that non-native species better align management plans with desired practice (Conway et al., 2019).

Incidents across the NTS's other garden properties in recent years have raised awareness and made explicit the need to be vigilant at the property level to monitor and react speedily to further incidents of new pests, diseases and invasive non-native plants (NTS BC13, 2013). To further explain how Inverewe has put this policy in to practice, the following case study is an account of a pest whose impact is being minimised, not eradicated, as there is no effective treatment available. This reality has required a change in approach, as living with enforced change to the collection is now an emerging truth, where experiential learning and the distillation of evidence gained from external parties is of real help to try to reduce the impact that change is bringing to the overall aesthetic integrity of the gardens. This shared practice is increasingly being seen as the way to help inform the future collection management and build an adaptive approach to maintain the spirit of place going forward.

\section{Case study 2: Chryseococcus arecae (golden root mealybug)}

Between August 2007 and December 2013 half of Inverewe's collection of Meconopsis (blue poppies) had been lost due to the accidental introduction of Chryseococcus arecae (golden root mealybug). The collection had been introduced by $\mathrm{Dr}$ Cowan, the then property manager at Inverewe, and, although not a national collection formally recognised by Plant
Heritage, it grew to consist of representatives of all the 'big perennial blue' types. These are no longer represented in the garden apart from container-grown specimens placed in a few choice areas.

Golden root mealybug is a sap-feeding insect that is native to New Zealand. It was first noticed in Britain in 2012 and is thought to be present only in Scotland (FERA, 2019). In its native New Zealand it does not cause serious damage to plants. Where infestations have been found in the UK, however, the performance of plants has been obviously affected. In the UK it seems to be particularly problematic to species of Meconopsis and Primula as it greatly impedes their growth; there is an obvious lack of vigour in terms of leaf size and infested plants do not 'bulk up' as is normal in herbaceous perennials. At Inverewe, not only is it present on the collection of Meconopsis but it has also been found on some of the Asiatic forms of Primula (including a candelabra cultivar named Primula 'Inverewe'). More recently it has been found on Lobelia tupa, Filipendula camtschatica, Veronicastrum virginicum 'Album', Heuchera 'Beauty Colour' and a form of Brachyglottis, though the latter species do not appear as badly affected as Meconopsis and Primula. Chryseococcus arecae is thought to be more problematic for species of Primula and Meconopsis because the roots are quite fleshy, and thus easy for the insect to feed upon, and the plants are relatively shallow rooted (Inverewe, 2013). When infestations of $C$. arecae are found on Meconopsis they have a tendency to congregate in numbers around the crowns, at the base of rosettes and behind spent leaf sheaths. It is not clear whether this is a breeding ritual or whether the insects are merely feeding in 
a sheltered spot, but feeding affects the vascular transport of water and nutrients between the roots and the leaves of the plant, which may explain the loss of vigour. Throughout the summer of 2014 the garden team undertook a trial treatment of C. arecae with nematodes. The nematodes were not specifically selected with $C$. arecae as the intended target but rather a broad range of other pests such as Otiorhynchus sulcatus (vine weevil) which are more commonly found in European nurseries and gardens. Having observed the state of many of the Meconopsis and Primula varieties that have had numerous applications of the nematode treatment it was concluded that this course of treatment was not having the desired effect.

Since then, Inverewe has suffered a catastrophic loss of its collection of Meconopsis and can only grow them as a pot culture and plunge in situ to flower for a small display for visitors. Primula is now grown in fresh ground and only in limited numbers. The focus of the collection is now directed towards the cultivation of Erythronium species, and cultivars which have been naturalised in large areas of Bambooslum and Rhododendron Walk for a number of years seem to be resistant to $C$. arecae so far.

\section{Future focus}

Chryseococcus arecae is a relatively new pest to the UK and a successful form of eradication has not yet been identified. In former times the way to treat it would have been to use a pesticide applied by means of a root drench, though there are currently no such chemicals specifically formulated for $C$. aracae. An insecticide based on thiacloprid, from German company Bayer, was originally thought to be a potentially useful product in controlling $C$. aracae as it is a systemic insecticide and would therefore be taken up by the plant and would poison the feeding insects. However, given the location of the garden in a biosphere reserve and adjacent to the Wester Ross Marine Protection Area, the exploration of a possible method of biological control, using predatory insects, is a preferred route and has the support of Kopperts Biological UK. To date, however, a particular approach has not been identified. One method that is practicable is to physically remove the insects by lifting the crowns, cleaning the roots of soil and killing any insects that are visible on the crowns before repotting the plants in a new, sterile medium. This is not a guaranteed means of success, however, because the insects can persist on the plant and garden soils would need to be kept fallow to prevent re-infestation (Foster, 2015).

\section{Case study 3: Pulvinaria floccifera syn. Chloropulvinaria floccifera (cottony camellia scale)}

This was first confirmed at Inverewe by Koppert Biological Systems on 11 October 2011. In the UK it has been found on a wide range of plant species including Choisya, Citrus, Euonymus, Juniperus, Kalmia, Laurus, Pieris, Pyracantha, Magnolia, Rhododendron, Taxus and Trachelospermum. In the autumn of 2011 Kevin Ball, Head Gardener at Inverewe, began work with Koppert to identify an effective treatment regime. The recommendation was to limit the scale insects by clearing a host 'weed' of the garden, Rhododendron ponticum, in order to provide a clear break between the horticulturally significant rhododendrons that were important to retain. Like all scale insects, it is a sap sucker feeding on the plant's vascular system, causing major cosmetic 
damage as well as growth reduction, leaf loss and slow dieback. In addition, it produces large amounts of honeydew upon which black, sooty fungus mould starts to grow, suffocating the plant, reducing its ability to photosynthesise and, again, severely damaging the aesthetics of the plant and garden as a whole. With such a large collection of rhododendrons (including three national collections) at Inverewe, this invasive pest was identified as a major problem and one that needed to be aggressively dealt with. Once one was familiar with the pest, infected plants were easily identified by the white ovisacs on the underside of the leaves, usually between 5 and $10 \mathrm{~mm}$ in length, and black sooty mould on the bark and tops of the leaves. In some areas where affected rhododendrons are in close proximity, this creates a very dark and oppressive atmosphere.

Initial treatments focused on removing the waxy protection of the pest, encouraging natural desiccation, while subsequent treatment has focused on the whole plant and soil health. The natural predators are encouraged to parasitise the scale through interventions designed to provide plants with good growing conditions and cultural care so they are naturally more resistant to scale damage. After four years of implementing an integrated pest management programme the garden had controlled but not eradicated the scale (Quinne, 2016). Certain areas within the garden, notably an area known as Devil's Elbow where the microclimate was very humid, were still a cause for concern; the density of canopy had meant little air movement was facilitated between large specimens. This has subsequently been addressed through thinning canopies to improve light and airflow, resulting in less still air. The understorey of Rhododendron ponticum has been almost completely removed from the shelterbelt and leading edge of the garden. It was an enormous reservoir for re-infestation, so now the garden is almost scale-free in some areas but requires ongoing interventions of treatment to soil, retained plants and encouraging natural predators.

\section{Future focus}

There is currently a lack of formally recognised and accepted controls for Pulvinaria floccifera, and so Inverewe, as a partnership project with Kopperts Biological UK, is collaborating to find a solution that allows the plants to thrive. The reduction in listed products continues, with Savona soft soap, the previously widely used treatment, being removed in 2018 from the list of approved products for use in the UK and leaving no alternative available for use as part of an integrated pest management system. The search for a balanced garden ecosystem therefore continues to be the best long-term means to live with the pest. The current focus is on increasing individual plant vitality through optimal growing conditions via improved drainage and amelioration by using on-site compost and Koppert plant-derived organic additives that stimulate naturally occurring soil microflora and micro-faunal activity (Foster, 2013; 2015).

\section{Discussion: solutions and learning from the past to inform the future}

This article has presented the start of an integrated approach to sustainable land use management at Inverewe in the context of episodic weather and increased exposure to novel pests and diseases. The link to climate change has been established, with the 
understanding that unprecedented rates of change are predicted to occur over the next 100 years as a result of human activity (IPCC, 2014). While the specific impacts of climate change are uncertain for collections such as those at Inverewe, the extreme forces at play are already evident. Therefore Inverewe, as a garden on the edge, represents an ideal model to review the impact of these and explore adaptations to its collection management, while aspiring to a resilient garden for future generations to inherit. An integrated approach is required that continually explores the theory and practice of collection and garden management at a time of global change (Frediani, 2008; Frediani et al., 2009).

Three case studies have been used to inform the discussion herein:

1. A pathogen of diverse host range mainly in woody plants, Phytophthora ramorum, has enforced the premature removal of a significant number of shelterbelt trees and sped up the removal of Rhododendron ponticum, which was originally planted as a understorey wind break. This removal has changed the dynamics of the garden and necessitated the selection and planting of evergreen non-native shrubs.

2. A root-borne pest that feeds on herbaceous plants has severely restricted cultivation of notable collections of Meconopsis and Primula at Inverewe in recent times.

3. A scale insect that exudes honeydew and is in turn fed on by mildew. The combined efforts severely reduce the vitality of rhododendrons at Inverewe.

A fourth case study has been inferred throughout the text: the emerging impact of climate change resulting in increased frequency of extreme weather events, visualised in Table 1 above.

Plant health problems can arise at any time and most potential problems are still considered relatively rare (Kendle, 2004). Some pest and diseases are common but not debilitating and can be avoided or mitigated to a greater or lesser degree with the use of a highly flexible strategy: avoidance of susceptible plants. However, in an established collection where specialist plant knowledge and a number of susceptible plants have been accrued over time and which have established national collection status, it is not possible to avoid this risk by selecting less susceptible species without impacting the collection policy and the amenity of the garden (Hohn, 2007).

Inverewe has identified a number of priority themes to inform action learning over the coming years:

- $\quad$ The need for deep and urgent changes to land management due to the rapidly increasing impact of climate change. These could include improved plant selection informed through current knowledge such as i-Tree Eco (i-Tree, 2019), Hemery et al. (2010) and Hirons \& Sjöman (2018).

- The need for more work on surveillance, prevention and response to emergent pests and diseases such as Xylella fastidiosa. This could be through early detection and identification, propagation of own nursery stock or, when bought in, application of rigid biological security and screening of new plant material in the nursery before it enters the garden.

- The importance of soil management for climate change adaptation, to encourage plant vitality and for wider carbon storage and plant sequestration. This 
could include better management of soil structure, improved drainage, unimpeded rooting and increased soil flora activity.

- The need to encourage and inform networks of a shared community of interest, in order to share experiences of events that have impacted gardens and their collections. National and international networks may provide the opportunity to share insight into successful interventions that protect collections for the benefit of all.

- The continued integration and review of plant health planning into the garden's strategy, through periodic reviews of the Inverewe Garden Heritage Garden Management Plan version 20.4.

It is known that many damaging pest and disease outbreaks are not random but are linked to environmental conditions, and they can reflect other problems such as poor soil conditions and plant handling (Kendle, 2004). The drainage, fertility, $\mathrm{pH}$ and other characteristics of the site will have an effect on the performance and appearance of the plants growing there (Kendle \& Sherman, 2004). This means that in the future the specification of sound cultural techniques can be applied to reduce the likelihood of such attacks reoccurring, and experimentation with new species and cultivars will increase the diversity of species and the potential of a resilient garden. In the interim, at Inverewe the collection is being monitored. Phenotypic plasticity is a mechanism with which organisms can cope with a changing climate; individuals with this capacity can respond to change within their lifetime (Williams et al., 2008). This is thought to be particularly important for species with long generation times, because evolutionary responses via natural selection may not produce change quickly enough to mitigate the effects of a warmer climate. Observation, in the same way as Osgood and Mairi fostered the early garden, will help to ensure that careful selection and a holistic management approach to the garden ecosystem continues to inform the direction of the collection in the years to come.

\section{Acknowledgements}

The author wishes to thank Kevin Ball, Inverewe Head Gardener, for all his help in provision of key information and dates that helped inform the article. Thanks also go to an anonymous reviewer who has enriched the content while allowing the author to reflect on the value of collaborative networks to help resolve what is an emerging global issue facing our heritage and botanic gardens.

\section{References}

BARBER, A.J., BEACH, A., PARK, R.G., TARNEY, J. \& STEWART, A.D. (1978). The Lewisian and Torridonian Rocks of North-West Scotland. Geologists' Association Guide No. 21. Geologists' Association, London.

BISGROVE, R.J. \& HADLEY, P. (2002). Gardening in the Global Greenhouse: The Impacts of Climate Change on Gardens in the UK, Technical Report. UKCIP, Oxford.

BUTLER, P. (2010). Eighty Years in the Highlands - The Life and Times of Osgood H. Mackenzie of Inverewe 1842-1922. Librario Publishing Ltd., Kinloss.

BUTLER, P. (2018). On building Inverewe: the house I built must precious be... Family and Homes 1860s-1953. National Trust for Scotland, Edinburgh.

CLOUGH, P. (2001). Inverewe Guidebook. National Trust for Scotland, Edinburgh.

CONWAY, T.M., ALMAS, A.D. \& COORE, D. (2019). Ecosystem services, ecological integrity, and native species planting: how to balance ideas in urban management? Urban Forestry \& Urban Greening, 41: $1-5$. 
COSGROVE, S. (2017). Inverewe botanical garden and house credits events and capital investment for strong start to 2017 season. Horticulture Week. Available online: www.hortweek.com/ inverewe-botanical-garden-house-credits-eventscapital-investment-strong-start-2017-season/ parks-and-gardens/article/1432148 (accessed June 2019).

COWAN, M. (1964). Inverewe: Garden in the North-west Highlands. Geoffrey Bles, London.

DARLING, F. (1945). Crofting Agriculture - its Practice in the West Highlands and Islands. Oliver \& Boyd Ltd., Edinburgh.

ESC4 (2019). Ecological Site Classification Decision Support System (ESC-DSS) Forest Research. Available online: www.forestresearch.gov.uk/tools-andresources/forest-planning-and-management-services/ ecological-site-classification-decision-supportsystem-esc-dss (accessed June 2019).

FERA (2019). UK Risk Register Details for Chryseococcus arecae. Available online: https:// secure.fera.defra.gov.uk/phiw/riskRegister/view PestRisks.cfm?cslref=27237 (accessed June 2019).

FOSTER, D. (2013). Report on Inverewe garden visit Week 34 (20th August 2013). Inverewe internal report.

FOSTER, D. (2015). Crop Report Week 29 (14 July 2015) Inverewe internal report.

FREDIANI, K. (2008). The ethical use of plants in zoos: informing selection choices, uses and management strategies. International Zoo Yearbook, 43(1): 29-52.

FREDIANI, K. (2018). The garden on the edge: Project proposal. National Trust for Scotland internal document.

FREDIANI, K., BUCKLAND, A., HANSFORD, D. \& ROGERS, K. (2019). Inverewe: Environmental Benefits Assessment 2018. National Trust for Scotland, Edinburgh.

GRACE, J. (1987). Climatic tolerance and the distribution of plants. New Phytologist, 106(1): 113-130.

GRANT, R. (2014). Inverewe Garden Heritage Garden Management Plan version 20.4. The National Trust for Scotland Gardens and Designed Landscape, Edinburgh.

HEMERY, G.E., CLARK, J.R., ALDINGER, E.,
CLAESSENS, H., MALVOLTI, M.E., O'CONNOR, E., RAFTOYANNIS, Y., SAVILL, P.S. \& BRUS, R. (2010). Growing scattered broadleaved tree species in Europe in a changing climate: a review of risks and opportunities. Forestry, 83: 65-81.

HIRONS, A.D. \& SJÖMAN, H. (2018). Tree species selection for green infrastructure: a guide for specifiers. Trees and Design Action Group Publications. Available online: www.tdag.org.uk/ species-selection-for-green-infrastructure.html (accessed June 2019).

HISTORIC ENVIRONMENT SCOTLAND (2017). Inverewe GDL00226. Inventory Garden \& Designed Landscape. Available online: portal. historicenvironment.scot/designation/GDL00226 (accessed June 2019).

HITCHMOUGH, J. \& FIELDHOUSE, K. (2004). Plant User Handbook: A Guide to Effective Specifying. Blackwell Publishing, London.

HITCHMOUGH, J. \& THODAY, P. (2004).

Introduction to plant use in the landscape. In: HITCHMOUGH, J. \& FIELDHOUSE, K. (eds), Plant User Handbook: A Guide to Effective Specifying. Blackwell Publishing, London, pp. 3-6.

HOHN, T. (2007). Curatorial Practices for Botanic Gardens. Altamira Press, Lanham, MD.

\section{INTERGOVERNMENTAL PANEL ON CLIMATE}

CHANGE (2014). Climate Change 2014: Synthesis Report. Contribution of Working Groups I, II and III to the Fifth Assessment Report of the Intergovernmental Panel on Climate Change (PACHAURI, R.K. \& MEYER, L.A., eds), IPCC, Geneva.

INVEREWE (2013). An assessment of the Inverewe Meconopsis Collection. Inverewe internal report.

I-TREE (2019). i-Tree Software Suite v6. Available online: https://species.itreetools.org (accessed August 2019).

JOHNSON, O. (2011). Champion Trees of Britain and Ireland: The Tree Register Handbook. Royal Botanic Gardens, Kew, Richmond.

KENDLE, T. (2004). The long term health of plants. In: HITCHMOUGH, J. \& FIELDHOUSE, K. (eds), Plant User Handbook: A Guide to Effective Specifying. Blackwell Publishing, London, pp. 89-92.

KENDLE, T. \& SHERMAN, B. (2004). Amelioration of underperforming soils. In: HITCHMOUGH, J. \& FIELDHOUSE, K. (eds), Plant User Handbook: A Guide 
to Effective Specifying. Blackwell Publishing, London, pp. 47-62.

LYTE, B., WARREN, J., HAENRAETS, J. \& MITCHELL, D. (2008). Garden shelterbelts - protecting yesterday's gardens tomorrow. Sibbaldia, 6: 181-188.

MACKENZIE, O. (1908). Gardening in the Western Highlands. Journal of the Royal Horticultural Society, 19: 47-53. Available online: www. biodiversitylibrary.org/item/164172\#page/9/ mode/1up (accessed June 2019).

NATIONAL TRUST FOR SCOTLAND (2013). Biosecurity Guidelines. Internal documents BC04; $\mathrm{BC} 05 ; \mathrm{BC} 06 ; \mathrm{BC} 13 ; \mathrm{BC} 20$. Gardens \& Designed Landscape Services of the National Trust for Scotland, Edinburgh.

OXFORD ENGLISH DICTIONARY (2019). Definition of 'garden'. Available online: en.oxforddictionaries.com/definition/garden (accessed June 2019).

PLANT HERITAGE (2019). Search Inverewe National Collections. Available online: www.nccpg. com/National-Collections/Collection-Results.aspx? keyword=inverewe\&county=\#search (accessed June 2019).

QUINNE, T. (2016). Final summary and recommendations for scale control programme. Inverewe Operational Report. National Trust for Scotland, Inverewe.

RODWELL, J.S. (ED.) (1991). British Plant Communities. Volume 1. Woodlands and scrub. Cambridge University Press, Cambridge.

RÖHRIG, E. \& ULRICH, B. (1991). Ecosystems of The World. 7: Temperate deciduous forests. Elsevier, Amsterdam.

SANSFORD, C.E., INMAN, A.J., BAKER, R., BRASIE,
C., FRANKEL, S., DE GRUYTER, J., HUSSON, C., KEHLENBECK, H., KESSEL, G., MORALEJO, E., STEEGHS, M., WEBBER, J. \& WERRES, S. (2009). Report on the risk of entry, establishment, spread and socio-economic loss and environmental impact and the appropriate level of management for Phytophthora ramorum for the EU. Deliverable Report 28. EU Sixth Framework Project RAPRA. Available online: https://secure.fera.defra.gov. uk/phiw/riskRegister/downloadExternalPra. $\mathrm{cfm}$ ?id=3802 (accessed June 2019).

SAWYER, M.T. (1953). Inverewe Guidebook. National Trust for Scotland, Edinburgh.

SCOTLAND'S ENVIRONMENT (2019). Climate trends. Available online: www.environment.gov. scot/data/data-analysis/climate-trends (accessed June 2019).

SJÖMAN, H., BUSSE NIELSEN, A., PAULEIT, S. \& OLSSON, M. (2010). Habitat studies identifying potential trees for urban paved environments: a case study from Qinling Mt., China. Arboriculture \& Urban Forestry, 36(6): 261-271.

STUDIO LR (2019). Inverewe: great experiences get great results. Available online: blog.studiolr. com/inverewe (accessed June 2019).

WALSH, S. (2016). PICTURES: Historic Inverewe House opens doors to public for first time after $£ 2$ million restoration. Available online: www.pressandjournal.co.uk/fp/news/ highlands/1015256/undefined-headline-1996 (accessed June 2019).

WILLIAMS, S.E., SHOO, L.P., ISAAC, J.L., HOFFMANN, A.A. \& LANGHAM, G. (2008). Towards an integrated framework for assessing the vulnerability of species to climate change. PLoS Biology, 6(12): 2621-2626. 